\title{
A de novo Synthetic Route to 1,2,3,4-Tetrahydroisoquinoline Derivatives
}

\author{
Synlett 2018, 29, 2066
}

The group of Professor Loránd Kiss at the Institute of Pharmaceutical Chemistry, University of Szeged (Hungary) has a profound interest in the development of selective methods for the synthetic access to highly functionalized fluorinated saturated heterocycles and $\beta$-amino acid derivatives. ${ }^{1}$ Organofluorine chemistry is an expanding research field, having led to various applications of fluorine-containing compounds in organic synthesis, materials science, medicinal chemistry and drug discovery. ${ }^{2}$

Because of the high biological relevance of compounds possessing the 1,2,3,4-tetrahydroisoquinoline framework, a large number of synthetic approaches towards the creation of an isoquinoline or 1,2,3,4-tetrahydroisoquinoline core are presently known. ${ }^{3}$ However, synthetic routes to tetrahydroisoquinoline derivatives containing fluorine atom(s) in their structure are not particularly abundant. ${ }^{4}$ The aim of the team from the laboratory of Professor Kiss was to fill this gap and develop effective synthetic methodologies to access varied fluorinated 1,2,3,4-tetrahydroisoquinoline derivatives. The two procedures used most frequently for the incorporation of fluorine atoms into the skeleton of an organic scaffold are:

a) late-stage fluorination protocols using either nucleophilic or electrophilic fluorinating reagents, and

b) the application of various fluorine-containing building elements in a certain stage of the synthesis.
Professor Kiss said: "In order to reach the current goal we have used the second protocol to create fluorinated tetrahydroisoquinoline derivatives. The novel synthetic route we have developed is based on an oxidative ring opening/ring closing with reductive amination protocol. ${ }^{5}$ The synthesis starts from indene and some substituted indene derivatives and, as key steps, it involved olefin bond cleavage through dihydroxylation/ $\mathrm{NaIO}_{4}$-mediated oxidation followed by cyclization with primary amines under reductive amination conditions."

The diols, derived from $\mathrm{OsO}_{4}$-catalyzed dihydroxylation of indene derivatives, were subjected to oxidative ring cleavage with NaIO4. The formed unstable diformyl intermediates, after work-up with extraction without isolation, were further transformed with commercially available fluorine-containing primary amines to give the target tetrahydroisoquinoline compounds in two steps (Scheme 1).

"The two-step protocol consists of reductive amination of diformyl intermediates with difluoroethylamine, trifluoroethylamine, fluoroethylamine or perfluorinated amines in the presence of $\mathrm{NaBH}_{3} \mathrm{CN}$, through cyclization with ring expansion, and leads to the corresponding tetrahydroisoquinoline derivatives 1-7 in moderate to good yields (Figure 1)," explained Professor Kiss. He continued: "The synthetic procedure was further extended by using indene derivatives substituted

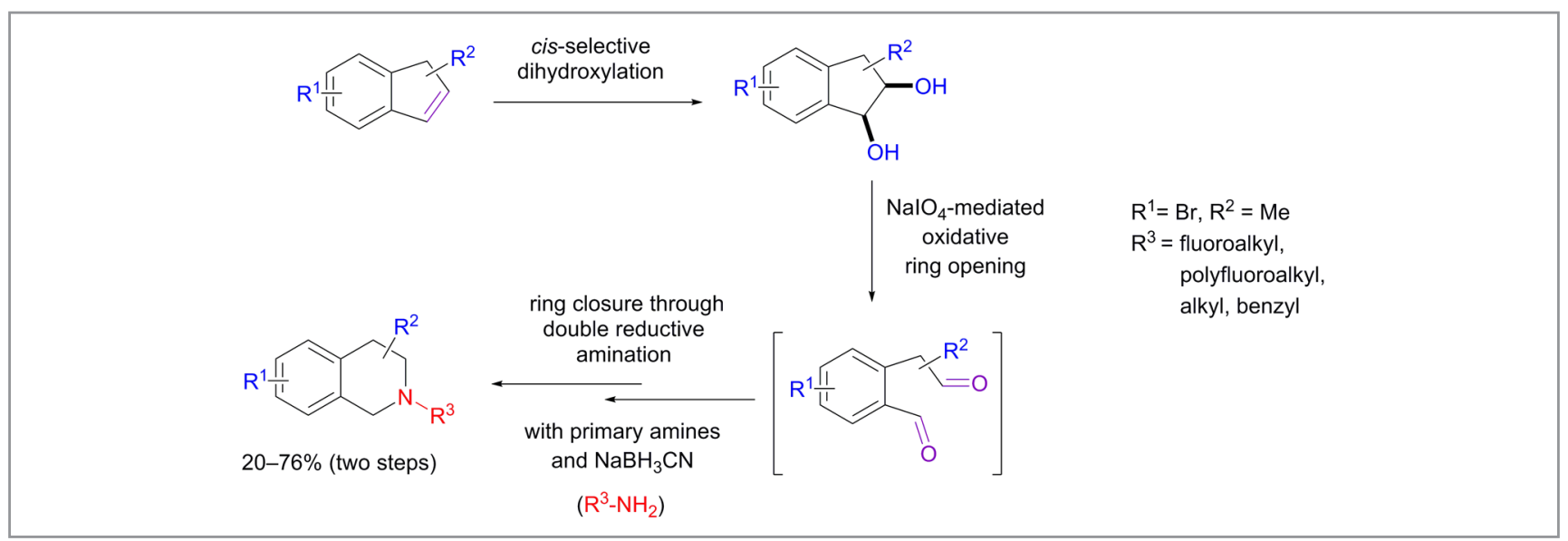

Scheme 1 Synthetic strategy 
<smiles>FC(F)CN1CCc2ccccc2C1</smiles>

$1(31 \%$, two steps)<smiles>FC(F)(F)CN1CCc2ccccc2C1</smiles>

$2(20 \%$, two steps)<smiles>FCCN1CCc2ccccc2C1</smiles>

3 (76\%, two steps)<smiles>CC(N1CCc2ccccc2C1)C(F)(F)F</smiles>

4 (34\%, two steps)<smiles>FC(F)(F)C(F)(F)C(F)(F)CN1CCc2ccccc2C1</smiles>

5 (24\%, two steps)<smiles>FC(F)(F)C(F)(F)C(F)(F)CN1CCc2ccccc2C1</smiles>

6 (53\%, two steps)<smiles>FC(F)(F)C(F)(F)CCN1CCc2ccccc2C1</smiles>

7 (28\%, two steps)<smiles>FC(F)(F)CN1CCc2c(Br)cccc2C1</smiles>

8 (53\%, two steps)<smiles>FC(F)CN1CCc2c(Br)cccc2C1</smiles>

9 (55\%, two steps)<smiles>CC1Cc2ccccc2CN1CC(F)(F)F</smiles>

$10(33 \%$, two steps)<smiles>CCN1CCc2ccccc2C1</smiles>

11 (59\%, two steps)<smiles>CCCCN1CCc2ccccc2C1</smiles>

12 (23\%, two steps)<smiles>c1ccc(CN2CCc3ccccc3C2)cc1</smiles>

$13(69 \%$, two steps)

Figure 1 Reaction scope

either on the benzene or on the five-membered ring. Accordingly, 7-bromo- $1 \mathrm{H}$-indene and 2-methyl- $1 \mathrm{H}$-indene were selected as model starting compounds to furnish the corresponding isoquinoline derivatives $\mathbf{8 - 1 0}$ through the oxidative ring opening/reductive ring closing technique (Figure 1)."

Finally, the group also explored the applicability of the developed method towards various non-fluorinated substances. Professor Kiss remarked: "The generalization of this procedure was demonstrated by using three different primary amines: ethylamine, butylamine, and benzylamine. Cyclization of the diformyl intermediate in the reaction with these amines produced the corresponding N-substituted tetrahydroisoquinoline derivatives 11-13 in moderate yields (Figure 1)."

"In summary, we developed a relatively simple and efficient procedure for the construction of 1,2,3,4-tetrahydroisoquinoline systems possessing various fluorine-containing or non-fluorinated substituents," said Professor Kiss. He concluded: "This method, based on oxidative ring cleavage of the olefinic bond of indene or indene derivatives followed by reductive ring closure through double reductive amination of diformyl intermediates using fluorinated amines, might be further extended towards other tetrahydroisoquinoline derivatives. We are currently investigating other applications of the method."

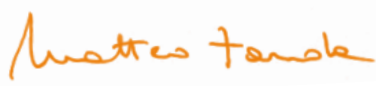

\section{REFERENCES}

(1) L. Kiss, F. Fülöp Chem. Rec. 2018, 18, 266-281.

(2) J. Wang, M. Sánchez-Roselló, J. L. Aceña, C. del Pozo,

A. E. Sorochinsky, S. Fustero, V. A. Soloshonok, H. Liu Chem. Rev. 2014, 114, 2432-2506.

(3) (a) M. Chrzanowska, A. Grajewska, M. D. Rozwadowska Chem. Rev. 2016, 116, 12369-12465. (b) B. A. Hopkins,

J. P. Wolfe Chem. Sci. 2014, 5, 4840-4844.

(4) (a) T. Fujita, J. Ichikawa Fluorinated isoquinolines: synthesis, properties and applications, In Fluorine in Heterocyclic Chemistry, Volume 2: 6-Membered Heterocycles, V. Nenajdenko, Ed.; Springer International Publishing: Cham, Switzerland; 2014.

(b) Y. Kuninobu, M. Nagase, M. Kanai Angew. Chem. Int. Ed. 2015, 54, 10263-10266. (c) B. Zhang, A. Studer Org. Biomol. Chem. 2014, 12, 9895-9898. (d) T. Punirun, D. Soorukram, C. Kuhakarn, V. Reutrakul, M. Pohmakotr J. Org. Chem. 2018, 83, 765-782.

(5) (a) R. A. Ábrahámi, L. Kiss, P. Barrio, F. Fülöp Tetrahedron 2016, 72, 7526-7535. (b) L. Kiss, F. Forró, F. Fülöp, Beilstein J. Org. Chem. 2015, 11, 596-603. (c) R. A. Ábrahámi, L. Kiss, S. Fustero, F. Fülöp Synthesis 2017, 49, 1206-1213. 


\section{About the authors}

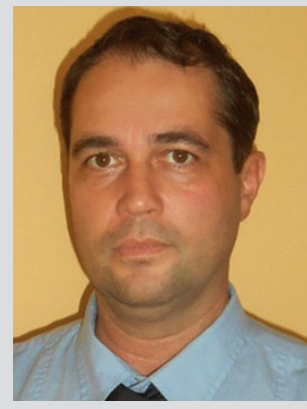

Prof. L. Kiss
Loránd Kiss completed his Ph.D. in 2002 in the Department of Organic Chemistry at the Faculty of Sciences, Debrecen University (Debrecen, Hungary) under the supervision of Prof. Sándor Antus. In 2003, he joined the research team of Professor Ferenc Fülöp at the Institute of Pharmaceutical Chemistry, University of Szeged (Szeged, Hungary), where he started to work in the area of cyclic $\beta$-amino acid chemistry. He undertook postdoctoral research in the laboratories of Prof. Norbert De Kimpe at Ghent University (Ghent, Belgium), and Prof. Santos Fustero at the Department of Organic Chemistry, University of Valencia (Valencia, Spain). He has published 90 scientific papers in reputable journals. He is currently professor and department head at the Institute of Pharmaceutical Chemistry, University of Szeged. His scientific interest is directed towards the selective functionalization of $\beta$-amino acid derivatives and the synthesis of highly functionalized fluorinated building blocks.

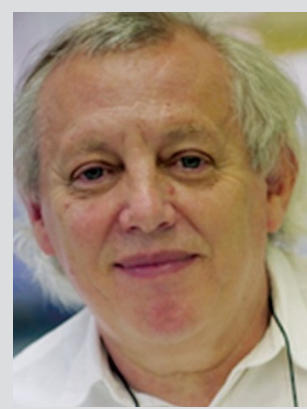

Ferenc Fülöp was born in Szank, Hungary in 1952. He received his MSc degree in chemistry in 1975 and his Ph.D. in 1979 from József Attila University (Szeged, Hungary). At the beginning of his career he worked in Chinoin Pharmaceuticals (Budapest, Hungary) for six years. In 1991, he was appointed as a full professor at the Institute of Pharmaceutical Chemistry, University of Szeged, and between 1998 and 2017 he was the

Prof. F. Fülöp

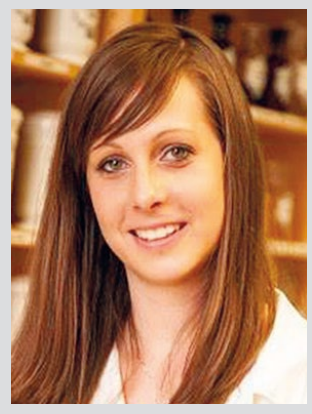

R. A. Ábrahámi

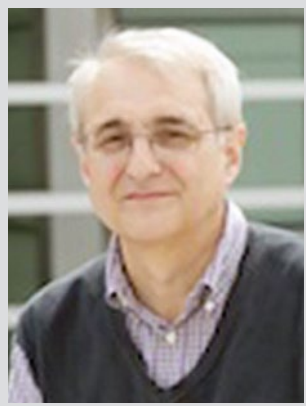

Prof. S. Fustero
Renáta A. Ábrahámi graduated as a pharmacist in 2015 from the University of Szeged (Hungary). She has been working at the Institute of Pharmaceutical Chemistry, University of Szeged since 2011. In 2015 she started her Ph.D. under the supervision of Loránd Kiss and Ferenc Fülöp. Her recent research topic focuses on the synthesis of varied functionalized six- or seven-membered saturated $\mathrm{N}$-heterocycles and on the preparation of highly substituted fluorinated building blocks.

Santos Fustero was born in Aínsa (Spain) in 1949. He studied chemistry at the University of Zaragoza (Spain), where he received his B.Sc. degree in 1972. He obtained his Ph.D. in organic chemistry in 1975 from the same university, working in the area of heterocyclic chemistry under the supervision of Professor ]. Barluenga and Professor V. Gotor. He spent two years as a postdoctoral research associate at Professor H. Lehmkuhl's laboratory at the Max-Planck-Institut für Kohlenforschung in Mülheim an der Ruhr (Germany), researching organometallic chemistry. In1983, he became an associate professor at the University of Oviedo (Spain) and, in 1990, he was promoted to full professor in organic chemistry at the University of Valencia (Spain). In 2005, he became research group leader at Centro de Investigación ‘Príncipe Felipe' (CIPF) in Valencia. His research interests include organofluorine and medicinal chemistry, organocatalysis, and new reaction methodologies.

head of the institute. He is a member of the Hungarian Academy of Sciences and has a wide range of research interests in synthetic organic chemistry. His recent activities have focused on the use of amino alcohols and $\beta$-amino acids in enzymatic transformations, various asymmetric syntheses, foldamer construction, and flow chemistry, in view of the development of pharmacologically active derivatives. 